\title{
The Effect of Naringin on the Apoptosis of Degenerative Nucleus Pulposus Cells: A Study on the Function and Mechanism
}

\author{
Zhenzhen Yuan*, Zhao Yang* \\ Orthopaedics, Tianjin Hospital, Tianjin, People's Republic of China \\ *These authors contributed equally to this work \\ Correspondence: Zhao Yang, Email anny.allan@I26.com
}

\begin{abstract}
Objective: The aim of this study was to explore the naringin suppressive effect on human degenerative nucleus pulposus cells (D-NPCs) apoptosis and its mechanism.

Methods: The degenerative NPCs were divided into 5 groups: the blank control $(0 \mu \mathrm{g} / \mathrm{mL}$ naringin $), 10 \mu \mathrm{g} / \mathrm{mL}, 20 \mu \mathrm{g} / \mathrm{mL}, 40 \mu \mathrm{g} / \mathrm{mL}$ and $100 \mu \mathrm{g} / \mathrm{mL}$ naringin group. Flow cytometry and CCK-8 assay were used to determine the influence on the cell apoptosis and viability in the presence of naringin among groups. The expressions of genes and proteins related to apoptosis and ECM were detected, respectively. Finally, the inhibitors or agonist of apoptotic pathways were used for experiments.

Results: In this study, we found naringin treatment led to a decrease of the D-NPCs apoptosis at an optimal concentration of $20 \mu \mathrm{g} / \mathrm{mL}$. After naringin treatment, the expressions of Wnt1 and $\beta$-catenin; Fas and Fasl; ATF-4 and CHOP; cleaved caspase-3 and caspase-8; $\mathrm{P} 53$ and $\mathrm{P} 16^{\mathrm{INK} 4 \mathrm{a}}$; pro-apoptotic protein Bax were down-regulated, while the expressions of anti-apoptotic protein Bcl-2, aggrecan and collagen II were up-regulated in human D-NPCs. The inhibitors or agonist of pathways could promote or reverse the decrease of apoptosis of degenerative NPCs induced by naringin.

Conclusion: Our data indicated that naringin had an antiapoptotic effect via inhibiting P53, P16 ${ }^{\mathrm{INK} 4 \mathrm{a}}$, Wnt/ $\beta$-catenin, and related apoptosis pathway, while the expression of ECM was increased in degenerative NPCs.
\end{abstract}

Keywords: apoptosis, naringin, nucleus pulposus cells

\section{Introduction}

Low back pain, one of the most common health problems, is a chronic, expensive, musculoskeletal disorder and over half the population of the world experience LBP at some point during their lifetime. ${ }^{1}$ Intervertebral disc (IVD) degeneration (IVDD) is a leading cause for LBP and other degenerative disc diseases. The normal IVD consists of an inner nucleus pulposus (NP), the outer fibrous region of annulus fibrosus (AF) and the cartilaginous endplates. NP cells play an important role in maintaining the physiological function of IVD by secreting extracellular matrix (ECM) components, such as aggrecan and type II collagen. A growing number of studies have demonstrated that reduced NP cells (NPCs) proliferation, aberrant apoptosis as well as ECM degradation, are key to IVDD pathogenesis. ${ }^{2,3}$

Apoptosis is type I programmed cell death, while inappropriate apoptosis is a factor in intervertebral disc degenerative diseases. There are three major signaling pathways triggering apoptotic cell death: the intrinsic (the mitochondrial) pathway, the extrinsic (the death receptor) pathway and endoplasmic reticulum (ER) pathway. These pathways converge on the activation of the caspase protease family, which is ultimately responsible for the dismantling of the cell. In addition, many upstream factors are involved in the regulation of apoptosis, such as p53, P16 ${ }^{\mathrm{INK} 4 \mathrm{a}}$ and wnt. $^{4}$

Naringin (4',5,7-trihydroxy-flavanone-7-rhamnoglucoside), a major flavanone glycoside that is found in grapefruit and extracted from a Chinese herbal medicine (Rhizoma Drynariae), has drawn growing attention for its various biological properties. ${ }^{5}$ Although Naringin may be beneficial in alleviating IVD degeneration, ${ }^{6}$ but the underlying 
mechanism remains blurry. The purpose of this study was to explore associated mechanisms for suppressive effects of NPCs apoptosis by naringin.

\section{Materials and Methods}

\section{Naringin and Reagents}

Naringin was purchased from Xi' an Guanyu Bio-tech Company (Xi'an, China). The purity of the compound was $\geq 98 \%$. Naringin was dissolved in dimethyl sulfoxide (DMSO, Sigma, USA) with a stock solution of $500 \mu \mathrm{g} / \mathrm{mL}$ prepared. All other chemicals and reagents were purchased from Sigma (USA) and Gibco (USA).

\section{Human NPCs Isolation and Culture}

The collection and use of human IVD specimens were approved by the Tianjin Hospital Ethics Committee. All samples were obtained during discectomy and intervertebral fusion surgery from 3 patients with IVDD (one woman and two men; age 68.33 \pm 7.78 ), and human NP specimens were classified as grade IV-V (IVDD discs) according to MRI. All patients signed a written informed consent form allowing the researchers to use IVD tissues obtained during spinal surgery. The study was conducted in accordance with the Declaration of Helsinki.

The NP tissue samples were separated and isolated immediately after surgery. The tissues were sliced into approximately $1 \mathrm{~mm}^{3}$ segments and digested at $37^{\circ} \mathrm{C}$ by $0.25 \%$ trypsin solution for $30 \mathrm{~min}$ and $0.2 \%$ type II collagenase for 3 hours. A sterile $100 \mu \mathrm{m}$ Nylon Mesh was used to filter the digested mixture. After isolation, the cells were cultured in DMEM/F12 medium with $10 \% \mathrm{FBS}$ (Gibco, USA) and $1 \%$ penicillin-streptomycin at $37^{\circ} \mathrm{C}$ in $5 \% \mathrm{CO}_{2}$ atmosphere, and media was changed every 3 days. The third generation of NPCs were used for subsequent experiments.

\section{CCK-8 Assay}

The degenerative NPCs at passage 3(P3) were divided into 5 groups: $0 \mu \mathrm{g} / \mathrm{mL}$ naringin (D-NPCs group with DMSO vehicle, blank control group), $10 \mu \mathrm{g} / \mathrm{mL}$ naringin group (cultured with DMEM/F12 medium containing $10 \mu \mathrm{g} / \mathrm{mL}$ naringin), $20 \mu \mathrm{g} / \mathrm{mL}$ naringin group, $40 \mu \mathrm{g} / \mathrm{mL}$ naringin group and $100 \mu \mathrm{g} / \mathrm{mL}$ naringin group. CCK-8 assay was used to determine the influence on the cell viability in the presence of naringin among groups. The cells were seeded into 96-well plates at $2 \times 10^{5}$ cells $/$ well with DMEM/F12 medium containing naringin $(0 \mu \mathrm{g} / \mathrm{mL}, 10 \mu \mathrm{g} / \mathrm{mL}, 20 \mu \mathrm{g} / \mathrm{mL}, 40 \mu \mathrm{g} / \mathrm{mL}, 100 \mu \mathrm{g} /$ $\mathrm{mL}$ ) at $37^{\circ} \mathrm{C}$ in $5 \% \mathrm{CO}_{2} .10 \mu \mathrm{L}$ CCK-8 was added into each well after $3 \mathrm{~d}$. The absorbance value (OD) of each well was detected by microplate reader at $450 \mathrm{~nm}$.

\section{Flow Cytometry}

After different treatments (control group with DMSO vehicle), the NP cells were harvested and washed with cold PBS. Apoptotic incidence was detected by staining Annexin V/PI apoptosis detection kit (Keygen, China). FC500MCL flow cytometry system was used for detection (Beckman). Apoptotic rate including the percentage of early (Annexin V+/PI-) and late (Annexin $\mathrm{V}+\mathrm{PI}+$ ) was calculated as the sum percentage of apoptotic cells.

\section{Quantitative Real-Time PCR (QRT-PCR)}

Naringin at $20 \mu \mathrm{g} / \mathrm{mL}$ was added to naringin group, while DMSO vehicle was applied to the control group for $3 \mathrm{~d}$, and then the supernatants of cells were collected. The total RNA of human NPCs was extracted using Trizol reagent (Invitrogen, USA), which was reverse transcribed into cDNA with Rever Tra Ace qPCR RT Kit (ToyoboCo. Ltd. Osaka, Japan). The gene relative expression was analyzed by $2^{-\Delta \Delta C T}$ method with GAPDH being housekeeper gene.

The Primers for target genes as follows: Wnt1:F5'-GAATCGCCGCTGGAACTGTC-3',R5'-GCGGAGGTGA TAGCGAAGATAAACG-3'; ;-catenin:F5'-TTCCAGACACGCTATCATGC-3',R5'-AATCCACTGGTGAACCAAGC-3'; Fas:F5'-CCAATTCTGCCATAAG-3',R5'-CACCTTTATTTGACGTGGGC-3';Fasl:F5'-TCTTCCCTGTCCAACCT CTG-3',R5'-CCAAGACCAACGGAACCATC-3';Caspase-8:F5'-GCATTAGGGACAGGAATGGA-3',R5'-CGACATAGG AGAGGGTACCT-3'GAPDH:F5'-GGTGGTCTCCTCTGACTTCAACAG-3',R5'-GTTGCTGTAGCC AAATTCGTTGTC-3'. All the primers were synthesized by Aoke Dingsheng Biotech (Beijing, China). 


\section{Western Blot}

Naringin at $20 \mu \mathrm{g} / \mathrm{mL}$ was added to naringin group, while DMSO vehicle was applied to the control group for $3 \mathrm{~d}$. The total protein in tissues and cells was extracted with RIPA lysis buffer, and the protein concentration was analyzed using BCA Quantitation Kit (Boster, Wuhan, China). Proteins were separated by SDS-PAGE, and transferred to polyvinylidene fluoride (PVDF) membranes. The membranes were blocked with 5\% skim milk and then incubated with primary antibodies against P16 ${ }^{\mathrm{INK} 4 \mathrm{a}}$ (1:200; Abcam), P53 (1:500; Abcam), Wnt1 (1:1000; Abcam), $\beta$-catenin (1:5000; Abcam), Fas (1:1000; Abcam), Fasl (1:1000; CST), Caspase-8 (1:500; Abcam), Bcl-2 (1:1000; Abcam), Bax (1:1000; Abcam), Cleaved caspase-3 (1:500; Abcam), CHOP (1:200; Abcam), ATF-4 (1:1000; Abcam), type II collagen (1:200; Abcam), aggrecan (1:100; Abcam), $\beta$-actin (1:5000; Abcam), espectively overnight at $4^{\circ} \mathrm{C}$. The membranes were incubated with horseradish peroxidase-conjugated (HRP) secondary antibodies (1:1000) for $1 \mathrm{~h}$. Blots were developed using enhanced chemiluminescence (Santa Cruz Biotechnology, CA, USA).

\section{Statistical Analysis}

Data were expressed as mean \pm standard deviation (SD). Statistical analysis was performed by one-way ANOVA or Student's $t$-test using software SPSS 21.0. $\mathrm{P}<0.05$ was considered for significance.

\section{Results}

\section{Cellular Morphology and Identification of Degenerated Human NP Cells}

The cells cultured were polygonal chondrocyte-like cells in shape, while Giemsa, safranin $\mathrm{O}$ and toluidine blue staining indicated that most cells were positively stained. Wright Giemsa staining showed that nucleus pulposus cells were polygonal or spindle, the nucleus was red purple, round or oval, and the cytoplasm was lightly stained (Figure 1C). SafraninO staining showed the cells are red stained, polygonal or spindle shaped and the cytoplasm is lightly stained, indicating that the cells can secrete proteoglycans (Figure 1D). Toluidine blue staining showed the cells are blue stained, the nuclei are blue and the matrix staining is slightly light, indicating that the cells can secrete glycosaminoglycans (Figure 1E).

\section{Effects of Different Doses of Naringin on the Apoptosis of NP Cells}

As the flow cytometry showed, compared with the blank control group, all naringin-treated groups suppressed the cell apoptosis at 3 day, while the naringin at $20 \mu \mathrm{g} / \mathrm{mL}$ resulted in a significant suppression of the NPCs apoptosis. The CCK- 8 assay indicated that all naringin-treated groups promoted the cell viability, whereas $20 \mu \mathrm{g} / \mathrm{mL}$ was more effective. In our study, the concentration of $20 \mu \mathrm{g} / \mathrm{mL}$ appeared most effective in inhibition of cell apoptosis and promotion of viability, thus adopted for subsequent experiments (Figure 2).

\section{Effect of Naringin on Gene and Protein Expressions of Wntl and $\beta$-Catenin}

As the results of qRT-PCR shown, Wnt1 and $\beta$-catenin were highly expressed in D-NPCs, while after $20 \mu \mathrm{g} / \mathrm{mL}$ naringin treatment, the expressions of Wnt1 and $\beta$-catenin were strongly reduced. After the D-NPCs were treatment with Wnt $/ \beta$ catenin pathway agonist $\mathrm{LiCl}(10 \mathrm{mmol} / \mathrm{L})$, and $20 \mu \mathrm{g} / \mathrm{mL}$ naringin $+\mathrm{LiCl}(10 \mathrm{mmol} / \mathrm{L})$, the gene and protein expressions of Wnt1 and $\beta$-catenin were increased, higher than that in $20 \mu \mathrm{g} / \mathrm{mL}$ naringin group. The results indicated that naringin might inhibit the D-NPCs apoptosis via $\beta$-catenin signaling pathway. In addition, agonist LiCl could reverse the decrease of Wnt/ $\beta$-catenin pathway expression induced by naringin, thus could reverse the protective effects of naringin on degenerative NPCs (Figure 3).

\section{Effect of Naringin on Gene and Protein Expressions of Fas, Fasl and Caspase-8}

As illustrated in Figure 4, the gene and protein expressions of Fas, Fasl and Caspase-8 were dramatically up-regulation in D-NPCs, while in the naringin-treating group, the expressions of Fas, Fasl and Caspase- 8 were remarkably downregulation. After the D-NPCs were treatment with Caspase-8 inhibitor KR-33493, and 20 $\mu \mathrm{g} / \mathrm{mL}$ naringin+KR-33493, the gene and protein expressions of Fas, Fasl and Caspase- 8 were decreased. Whereas the difference of the gene expression was not statistically significant between the KR-33493 and $20 \mu \mathrm{g} / \mathrm{mL}$ naringin group $(\mathrm{P}>0.05)$. The results demonstrated 
A

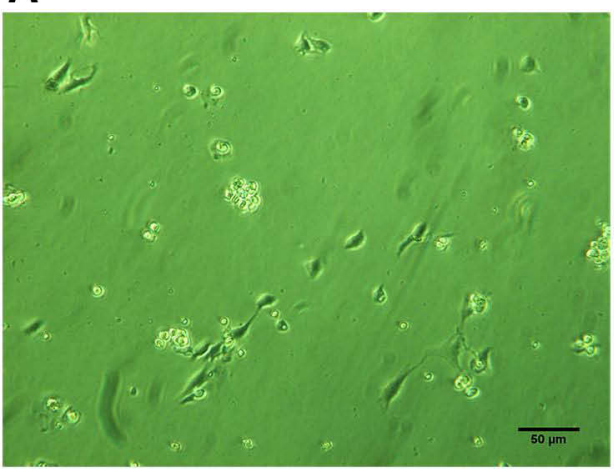

C

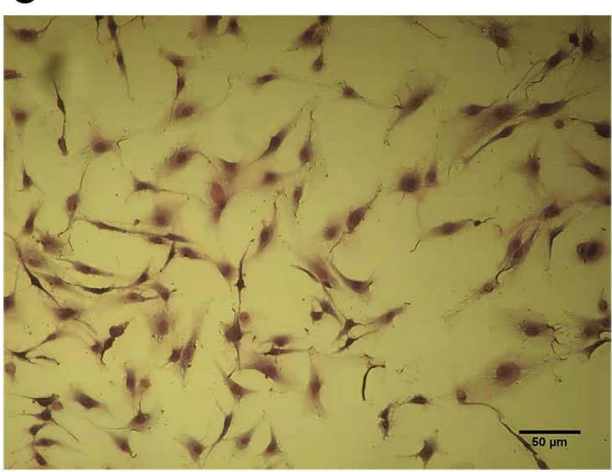

B

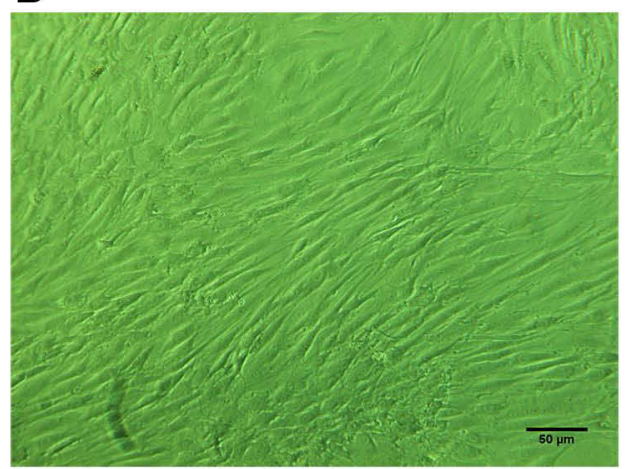

D

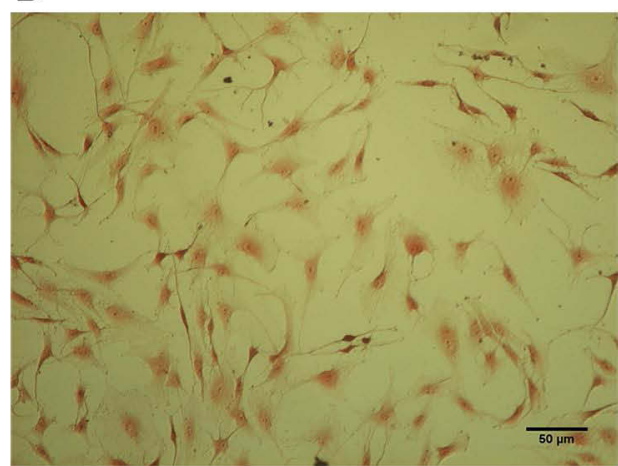

E

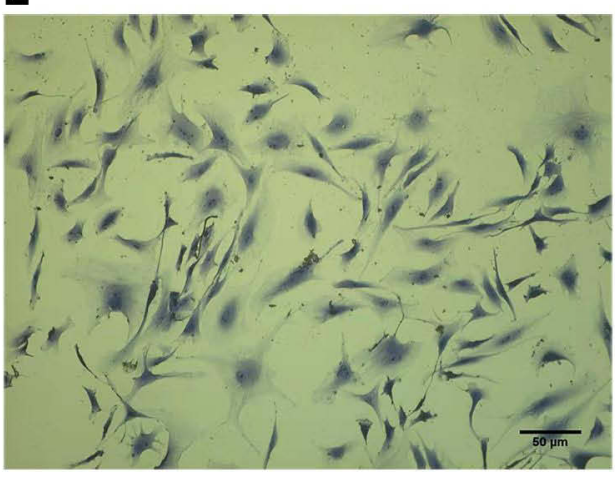

Figure I Cultivation and characterization of human D-NPCs. (A) NPCs cultured after I day. (B) NPCs cultured after 7 day. (C) NPCs stained by Giemsa. (D) NPCs stained by safranin O. (E) NPCs stained by toluidine blue. Scale bar $=50 \mu \mathrm{m}$.

that naringin had a highly significant suppressive effect on the expressions of Fas, Fasl and Caspase-8, thus naringin might inhibit apoptosis of D-NPCs via Fas/Fasl pathway.

\section{Effect of Naringin on Protein Expression of Bcl-2, Bax, Cleaved Caspase-3}

The results of western blot showed that the protein expression of Bcl-2 was low in D-NPCs, while Bax, Cleaved Caspase-3 were highly expressed. After naringin-treating at $20 \mu \mathrm{g} / \mathrm{mL}$, the expression of Bcl-2 was effectively promoted compared with the control group, and the expressions of Bax, Cleaved Caspase-3 were significantly down-regulated (Figure 5). In the ABT-263 (a Bcl-2 inhibitor) group, the protein expression of Bcl-2 was increased, while the expressions of Bax, Cleaved Caspase-3 were suppressed, the difference of the above protein expression was not statistically significant with $20 \mu \mathrm{g} / \mathrm{mL}$ naringin group $(\mathrm{P}>0.05)$. The results indicated that naringin might be through the regulation of the mitochondrial signaling pathway to inhibit the NPCs apoptosis. 
A

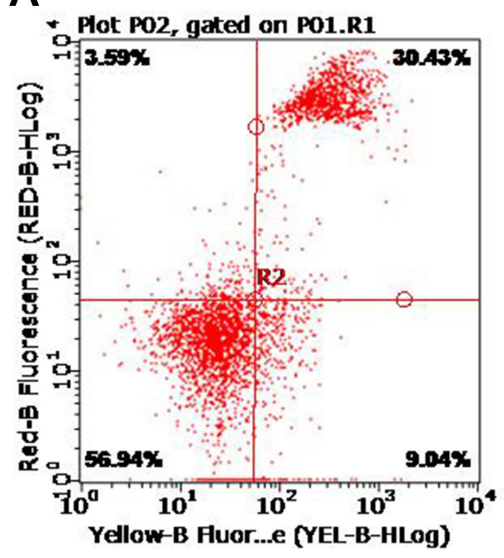

D

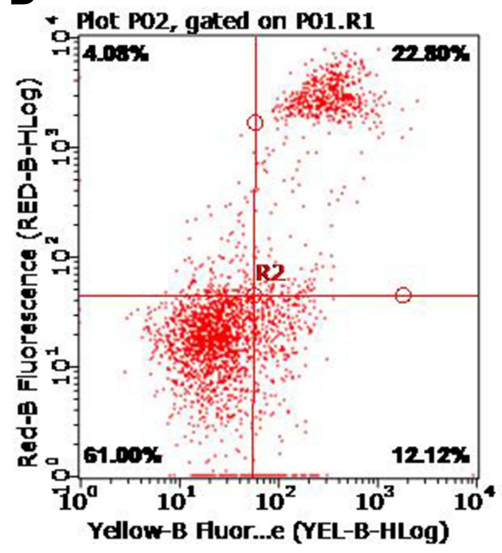

B

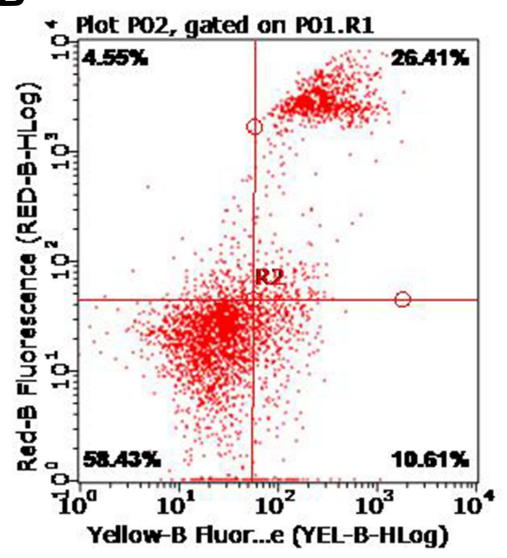

E

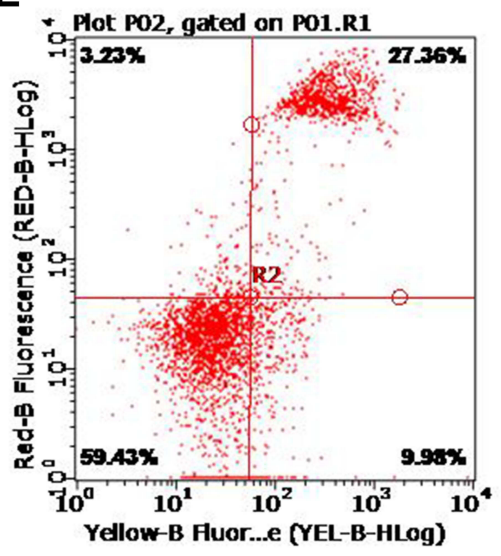

C

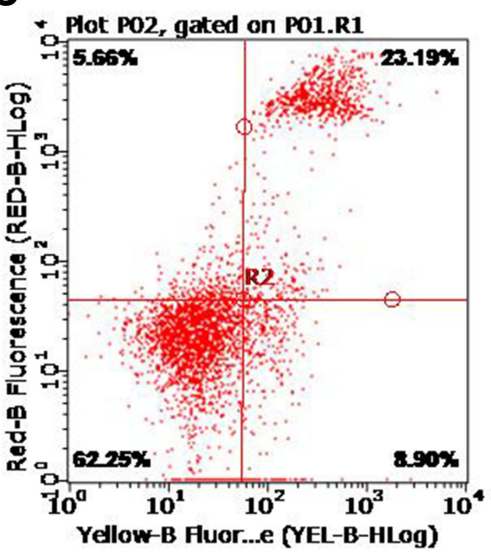

F

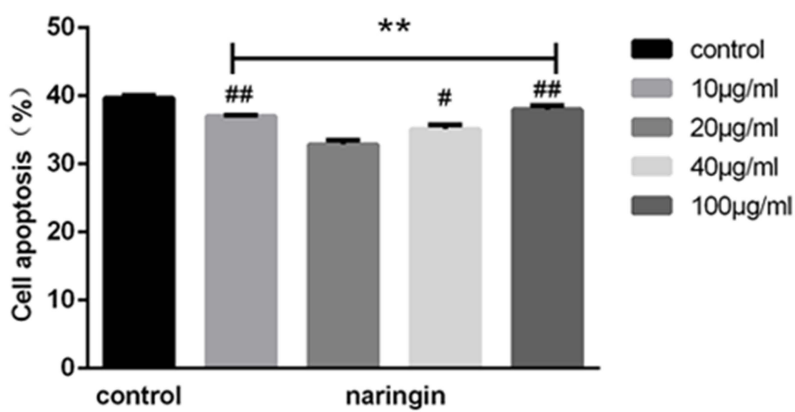

G

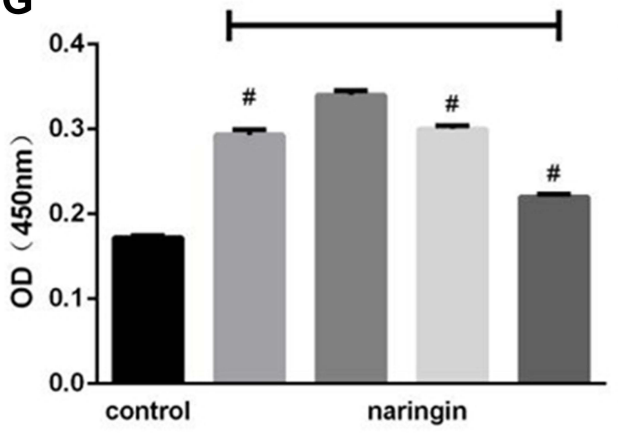

control

$10 \mu \mathrm{g} / \mathrm{ml}$

$20 \mu \mathrm{g} / \mathrm{ml}$

$40 \mu \mathrm{g} / \mathrm{ml}$

$100 \mu \mathrm{g} / \mathrm{ml}$

Figure 2 Effects of naringin on NPCs apoptosis and viability. (A-F) Flow cytometry of the NPCs apoptosis after naringin treatment in various concentration gradient, $n=3$. (A) blank control group, (B) $10 \mu \mathrm{g} / \mathrm{mL}$ Naringin group, (C) $20 \mu \mathrm{g} / \mathrm{mL}$ Naringin group, (D) $40 \mu \mathrm{g} / \mathrm{mL}$ Naringin group, (E) $100 \mu g / \mathrm{mL}$ Naringin group. (G) Datas of CCK-8 showed that the concentration of $20 \mu \mathrm{g} / \mathrm{mL}$ appeared most effective on the viability of NP cells, $n=6$. Data presented as mean $\pm S D$, $* P<0.05, * * P<0.0$ I vs control group; ${ }^{\#} P<0.05$, \#\# $\mathrm{P}<0.01$, vs $20 \mu \mathrm{g} / \mathrm{mL}$ naringin-treating group, as evaluated by ANOVA.

\section{Effect of Naringin on Protein Expression of ATF-4 and CHOP}

As shown in Figure 6, the protein expressions of ATF-4 and CHOP were significantly up-regulated in D-NPCs, while in the naringin-treating group, the expressions of ATF-4 and CHOP were remarkably down-regulation. After the D-NPCs were treatment with PERK pathway inhibitor GSK2606414, the protein expressions of ATF-4 and CHOP were decreased, whereas the difference of the protein expression of ATF-4 and CHOP was not statistically significant with 


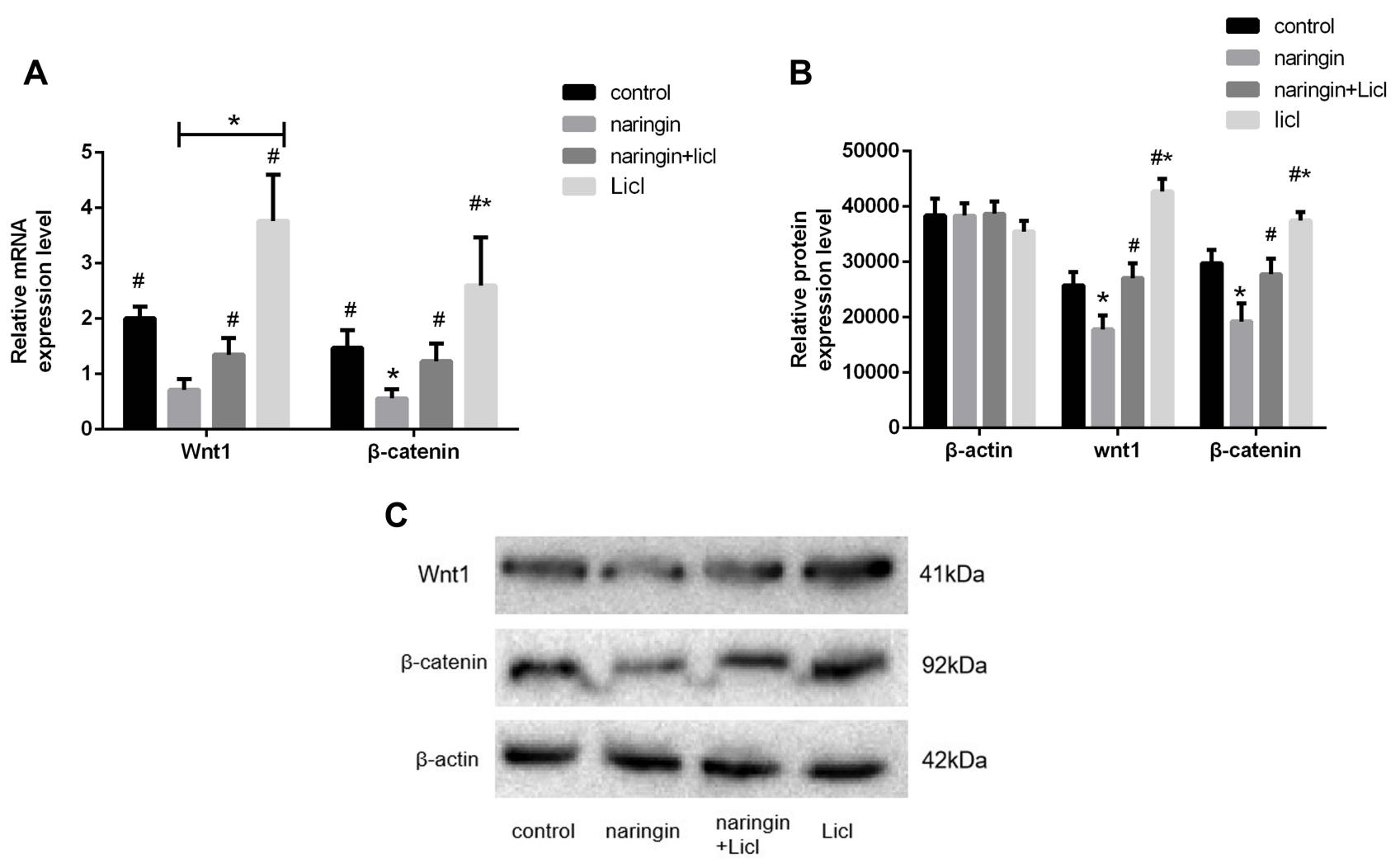

Figure 3 Effects of naringin on NPCs apoptosis via Wnt/ $\beta$-catenin pathway. (A) The gene expression of Wntl and $\beta$-catenin, $n=6$. (B and $\mathbf{C})$ The protein expression of $\mathrm{Wntl}$ and $\beta$-catenin, $\mathrm{n}=3$. Data presented as mean $\pm \mathrm{SD},{ }^{*} \mathrm{P}<0.05$, vs control group; ${ }^{\#} \mathrm{P}<0.05$, vs $20 \mu \mathrm{g} / \mathrm{mL}$ naringin-treating group, as evaluated by $\mathrm{ANOVA}$.

$20 \mu \mathrm{g} / \mathrm{mL}$ naringin group $(\mathrm{P}>0.05)$. The results demonstrated that naringin had a suppressive effect on the expressions of ATF-4 and CHOP, thus naringin might inhibit apoptosis of D-NPCs via PERK pathway.

\section{Effects of Naringin on the Protein Expression of P53 and PI6 ${ }^{\mathrm{INK} 4 a}$}

As illustrated in Figure 7, compared with the blank control group, naringin at $20 \mu \mathrm{g} / \mathrm{mL}$ dramatically suppressed the expressions of P53 and P16 ${ }^{\mathrm{INK} 4 \mathrm{a}}$ protein in D-NPCs, thus naringin might inhibit apoptosis of D-NPCs via downregulating $\mathrm{P} 53$ and $\mathrm{P} 16^{\mathrm{INK} 4 \mathrm{a}}$ protein.

\section{Effects of Naringin on the Protein Expression of Type II Collagen and Aggrecan}

Western blot results (Figure 8) showed that, compared with the control group, naringin at $20 \mu \mathrm{g} / \mathrm{mL}$ significantly promoted the expressions of aggrecan and collagen II protein in D-NPCs. Therefore, the above results demonstrated that naringin could enhance the ECM synthesis and secretion of D-NPCs.

\section{Discussion}

IVDD is the most common cause of degenerated disc diseases such as low back pain, sciatica, and spinal stenosis, which are enormous financial burdens to public health and society. ${ }^{7}$ Although its exact cellular and molecular mechanisms are not well known, it is widely accepted that NPCs play a key role in the development and deterioration of IVDD. ${ }^{8,9}$ The normal IVD is composed of three regions: an inner nucleus pulposus, the outer annulus fibrosus and the cartilaginous endplates. Previous studies have shown that NP cells play a crucial role in maintaining normal structure and functions of human IVD via secreting aggrecan and type II collagen. A growing number of studies have demonstrated that aberrant NP cell functions, including altered cell proliferation, apoptosis, ECM production/degradation and cytokine secretion, are key to IVDD pathogenesis. ${ }^{6,8-10}$ The ECM of NP cells is formed mainly by aggrecan and type II collagen which attract 


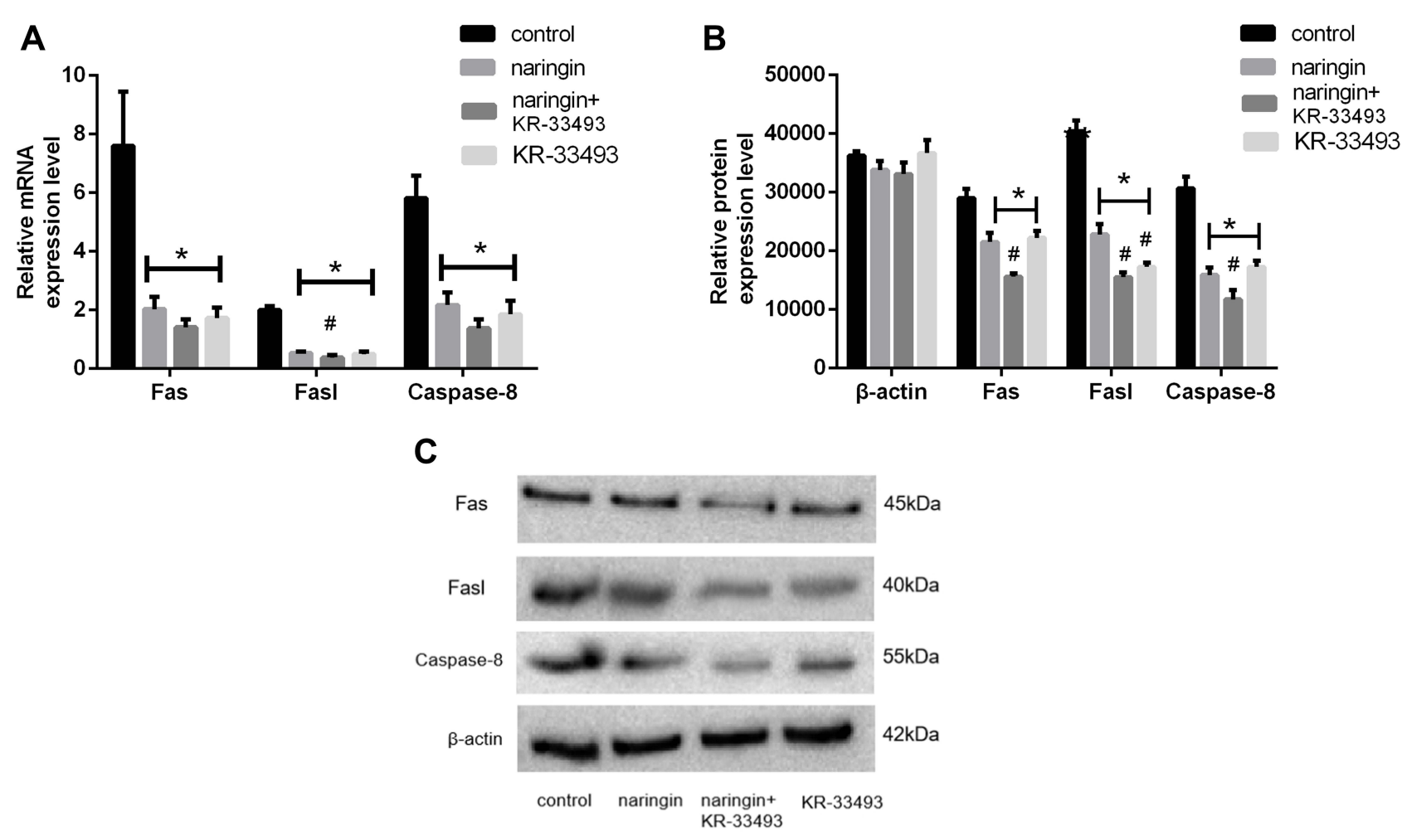

Figure 4 Effects of naringin on NPCS apoptosis via Fas/ Fasl pathway. (A) The gene expression of Fas, Fasl and Caspase-8, $\mathrm{n}=6$. (B and $\mathbf{C})$ The protein expression of Fas, Fasl and Caspase-8, $\mathrm{n}=3$. Data presented as mean $\pm \mathrm{SD}$, ${ }^{*} \mathrm{P}<0.05$, vs control group; ${ }^{\#} \mathrm{P}<0.05$, vs $20 \mu g / \mathrm{mL}$ naringin-treating group, as evaluated by ANOVA.
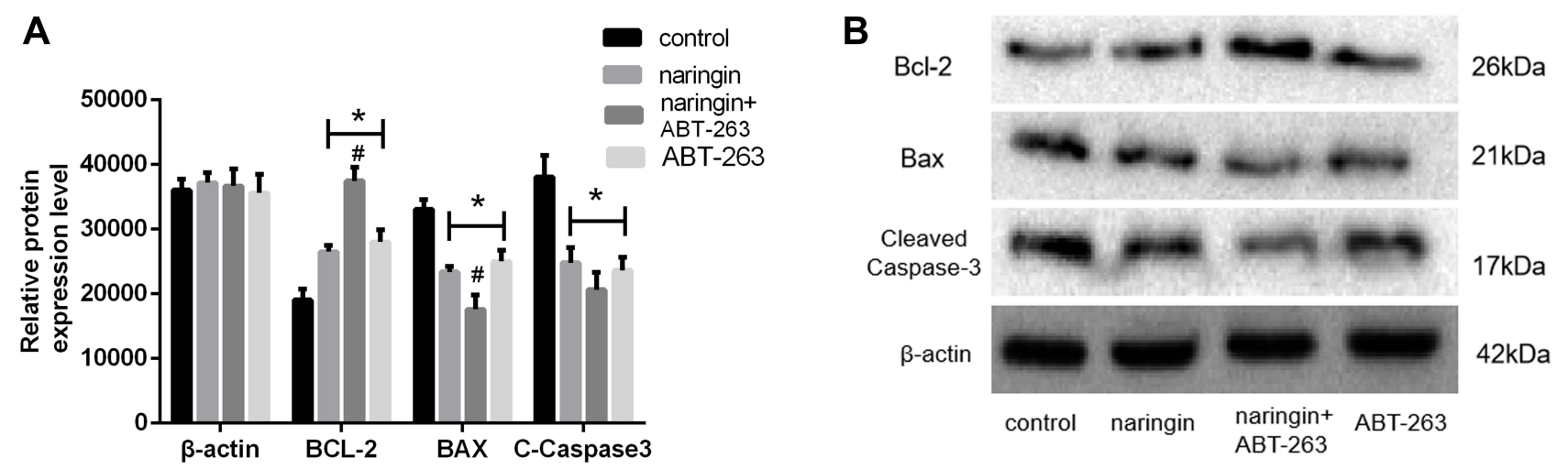

Figure 5 Effects of naringin on NPCs apoptosis via Mitochondrial pathway. (A and B) Protein expression of Bcl-2, Bax and Cleaved Caspase-3. Data presented as mean \pm SD, $\mathrm{n}=3$, $* \mathrm{P}<0.05$, vs control group, ${ }^{\#} \mathrm{P}<0.05$, vs $20 \mu \mathrm{g} / \mathrm{mL}$ naringin-treating group, as evaluated by ANOVA.

water molecules to resist axial compressive loads from the trunk. As revealed in this study, naringin at $20 \mathrm{ug} / \mathrm{mL}$ exhibited significant effects on promoting the secretion of aggrecan and type II collagen for maintaining the integrity of intervertebral discs.

It is well known that as a member of polyphenolic flavonoid family, naringin possesses various biological activities such as anti-oxidant, anti-inflammatory, anti-microbial, anti-osteoporosis, and anti-cancer activities. ${ }^{11}$ It has been reported that naringin may attenuate the severity of IVD degeneration, through inhibiting the local inflammation in NP tissue, as well as promoting NP cell proliferation. ${ }^{6}$ The results of CCK-8 found that a serial concentrations of naringin from $10 \mu \mathrm{g} / \mathrm{mL}$ to $100 \mu \mathrm{g} / \mathrm{mL}$ showed beneficial effects, although a dosage of $20 \mu \mathrm{g} / \mathrm{mL}$ demonstrated the most effective influence on inhibiting nucleus pulposus cell apoptosis. In vitro study, we showed for the first time that naringin inhibited nucleus pulposus cell apoptosis to reduce intervertebral disc degeneration via down-regulating Wnt signaling pathway, 

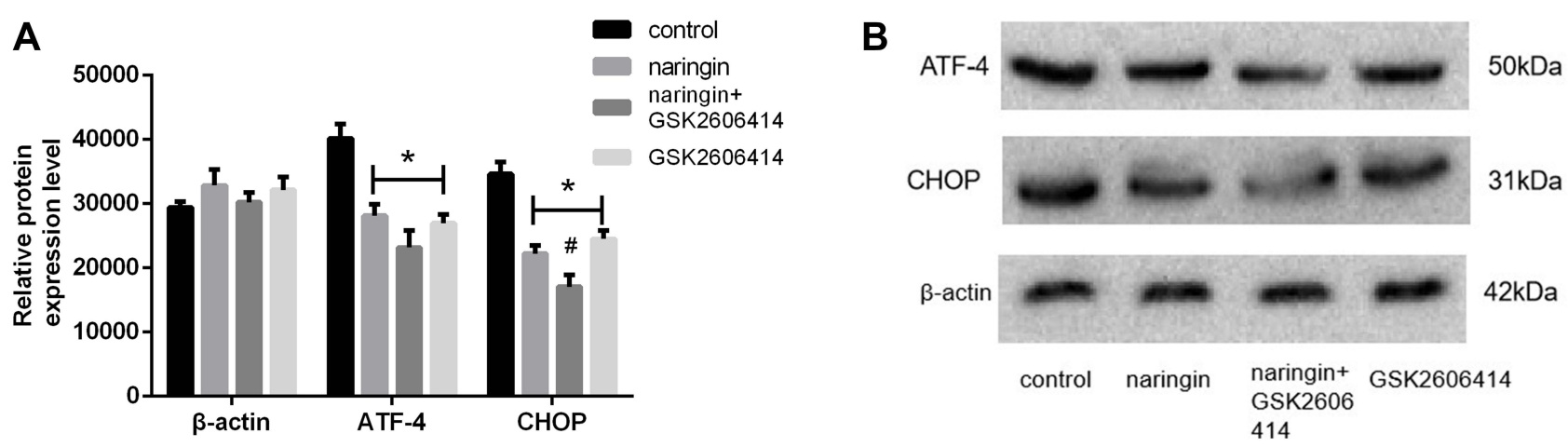

Figure 6 Effects of naringin on NPCs apoptosis via PERK pathway. (A and $\mathbf{B})$ Protein expression of ATF-4 and CHOP. Data presented as mean \pm SD, $n=3$, *P $<0.05$, vs control group, ${ }^{\#} \mathrm{P}<0.05$, vs $20 \mu \mathrm{g} / \mathrm{mL}$ naringin-treating group, as evaluated by ANOVA.
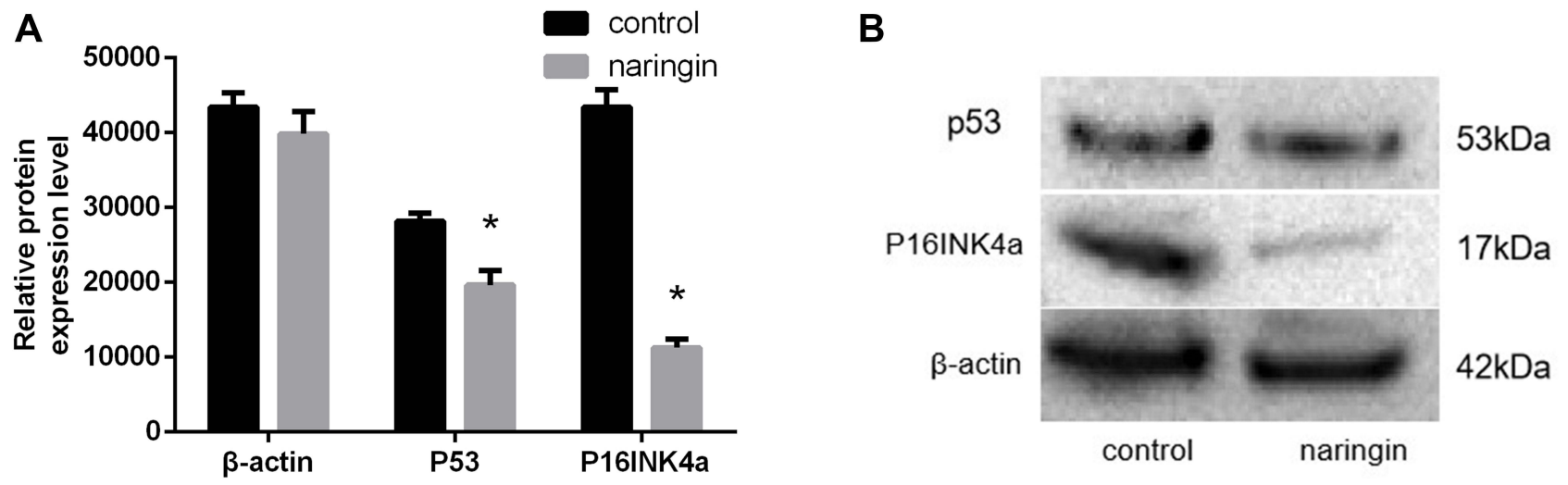

Figure 7 Effects of naringin on NPCs apoptosis via P53 and PI6 ${ }^{I N K 4 a}$. (A and B) Protein expression of P53 and PI6 ${ }^{I N K 4 a}$. Data presented as mean \pm SD, $n=3$, *P $<0.05$, vs control group, as evaluated by Student's t-test.
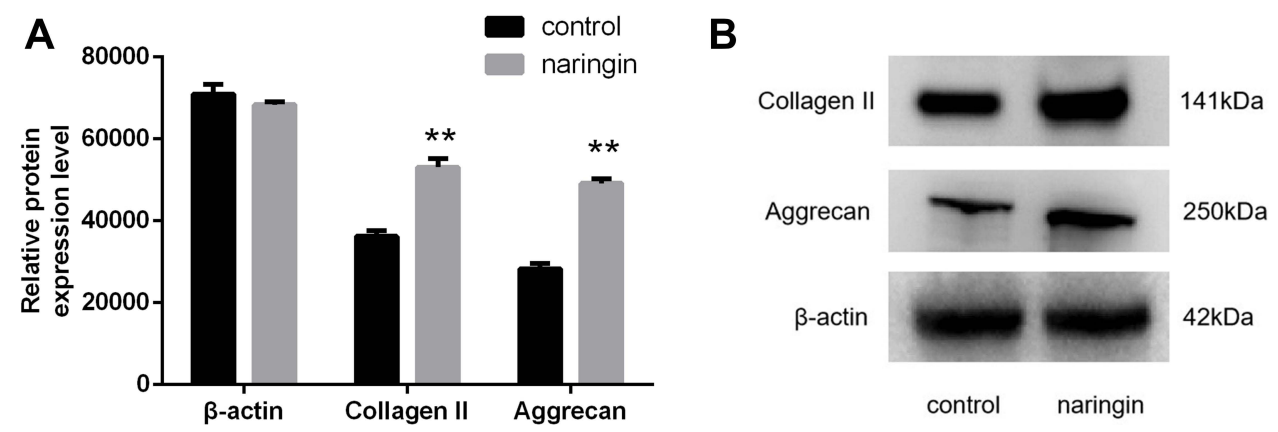

Figure 8 The expression of extracellular matrix detected following naringin treatment. (A and $\mathbf{B}$ ) protein expression of collagen II and aggrecan. Data presented as mean $\pm \mathrm{SD}, \mathrm{n}=3$, **P $<0.01$ vs control group, as evaluated by Student's $t$-test.

major apoptosis pathways, while the expressions of aggrecan and type II collagen were obviously increased after naringin treatment. Thus, naringin may be a potential therapeutic agent for IVDD.

Apoptosis is programmed cell death in order to remove harmful, damaged or unwanted cells, and also is responsible for pathogenesis of various diseases. ${ }^{12}$ It has been proposed that apoptosis in NPCs, is effective on IVDD by causing cellular loss, while the decrease in NPCs leads to decline in ability of synthesizing and repairing extracellular matrix. ${ }^{2,13}$ Diverse pathways that regulate cellular apoptosis in IVDD have been observed, mainly including death receptor pathway (Fas/Fasl), Mitochondrial and ER pathway. ${ }^{14}$ Fas/Fasl signaling way which can contribute to apoptotic cell death plays an important role in IVDD. It is widely accepted that mediators and downstream effectors of Fas/Fasl signaling are 
increased in IVDD, including Fas, Fasl and Caspases. ${ }^{15}$ It was reported that, in induced IVDD rats, Fas expression was demonstrated to be 8 -fold increased 3 weeks after annular laceration compared to normal IVD. ${ }^{14}$ Thus, Fas/Fasl signaling way is associated with the risk of IVDD. Caspase- 8 in caspase protein family is the initiator Caspase, which could activate executioner Caspases (Caspase-3, Caspase-6 and Caspase-7). ${ }^{16}$ Our results indicated that $20 \mu \mathrm{g} / \mathrm{mL}$ naringin could significantly reduce the expression of Fas, Fasl and Caspase- 8 to inhibit the apoptosis of NPCs for the improvement of IVDD.

The mitochondria pathway plays a crucial role in the NPCs apoptosis by inducing cytochrome c release, apoptosome formation, and Caspase activation. ${ }^{17}$ The mitochondrial pathway is carried on by regulation of Bcl-2 and Bax. Bcl-2 is antiapoptotic via blocking the function of Bax that is promoting apoptosis of nucleus pulposus cells. ${ }^{18}$ Both the intrinsic and the extrinsic apoptotic pathways converge at the level of effector caspases, such as Cleaved Caspase-3 and Caspase-7. Cleaved Caspase- 3 is the executioner caspase, which is ultimately responsible for the dismantling of the cell. ${ }^{19}$ As the results shown, the expression of Bcl-2 was down-regulated, while the expressions of Bax and Cleaved Caspase-3 were up-regulated in the degenerative NPCs. Naringin at $20 \mathrm{ug} / \mathrm{mL}$ dramatically increased the production of Bcl-2 and suppressed the expressions of Bax and Cleaved Caspase-3 in vitro. Consequently, as revealed in this study, naringin was effective to suppress apoptosis of NPCs in degenerative disc via the mitochondrial pathway.

Similar to the mitochondria pathway, the ER may also directly activate the PERK-ATF4-CHOP pathway triggering apoptosis. C/EBP homologous protein (CHOP) has been shown to be involved in nucleus pulposus cell apoptosis by arresting the cell cycle and inducing cell death. ${ }^{20}$ Overexpression of ATF-4 can induce a cascade of apoptotic factors and promote the expression of CHOP, which ultimately leads to cell death. ${ }^{21}$ In our study, we found that naringin could down regulate the expression of ATF-4 and CHOP through PERK-ATF4-CHOP pathway inhibiting nucleus pulposus cell apoptosis.

Wnt/ $\beta$-catenin signaling pathway is the canonical Wnt signaling pathway. An accumulating body of evidence suggests that Wnt/ $\beta$-catenin signaling plays crucial roles in cellular functions including proliferation, differentiation, apoptosis and migration. ${ }^{22}$ In parallel, aberrant Wnt signaling underlies a wide range of pathologies in humans. Studies have suggested that the deregulation of $\mathrm{Wnt} / \beta$-catenin has been documented in IVDD. ${ }^{23,24}$ Buchtova et al indicated that activation of Wnt/ $\beta$-catenin could reduce the proliferation of human NPCs, promote its apoptosis and suppress secretion of ECM in IVDD. ${ }^{24}$ Yu et al found that G-Rg1 could inhibit NPCs apoptosis in IVDD and promote ECM synthesis via inhibiting the Wnt $/ \beta$-catenin pathway. ${ }^{25}$ In the current study, the results of qRT-PCR found that, compared with GAPDH gene, the expressions of Wnt1 and $\beta$-catenin in degenerative NPCs were up-regulated, and that in $20 \mu \mathrm{g} / \mathrm{mL}$ naringin group were significantly lower than that in the D-NPCs group, whereas the agonist LiCl could reverse the results.

The P53 protein is an important factor that regulates the cell cycle and induces apoptosis. It has been shown that the P53 protein, as a transcription factor, inhibits the expression of Bcl-2, as well as promotes the expression of Bax, affects apoptosis through mitochondrial pathway. ${ }^{26}$ Beyond this, P16 ${ }^{\mathrm{INK} 4 \mathrm{a}}$ is also a key contributor to cause cell-cycle arrest and apoptosis in nucleus pulposus cells. ${ }^{27} \mathrm{P} 53$ and $\mathrm{P} 16^{\mathrm{INK} 4 \mathrm{a}}$ play functional roles in intervertebral disc degeneration. As the results shown, we proposed that inactivation of P53 and P16 ${ }^{\mathrm{INK} 4 \mathrm{a}}$ was involved in the beneficial role of naringin in inhibition of IVDD.

\section{Conclusion}

In our study, we demonstrated that naringin in vitro promoted apoptosis-antagonizing protein Bcl-2 expression, suppressed Wnt1 and $\beta$-catenin; Fas and Fasl; Cleaved Caspase-3 and Caspase 8; ATF4 and CHOP; P53 and P16 ${ }^{\mathrm{INK} 4 \mathrm{a}}$; pro-apoptotic protein Bax expression in D-NPCs. Taken together, our data demonstrated that naringin had an antiapoptotic effect by inhibiting Wnt/ $\beta$-catenin, Fas/Fasl, Mitochondrial and ER pathway, while aggrecan and collagen II were increased in degenerative NPCs. This study conferred a promising therapeutic strategy for disc degeneration.

\section{Disclosure}

The authors report no conflicts of interest in this work. 


\section{References}

1. Ruiz-Fernández C, Francisco V, Pino J, et al. Molecular relationships among obesity, inflammation and intervertebral disc degeneration: are adipokines the common link? Int J Mol Sci. 2019;20(8):2030. doi:10.3390/ijms20082030

2. Zheng Z, Wang Z-G, Chen Y, et al. Spermidine promotes nucleus pulposus autophagy as a protective mechanism against apoptosis and ameliorates disc degeneration. J Cell Mol Med. 2018;22(6):3086-3096. doi:10.1111/jcmm.13586

3. Zhang Y, He F, Chen Z, et al. Melatonin modulates IL-1 $\beta$-induced extracellular matrix remodeling in human nucleus pulposus cells and attenuates rat intervertebral disc degeneration and inflammation. Aging (Albany NY). 2019;11(22):10499-10512. doi:10.18632/aging.102472

4. Elmore S. Apoptosis: a review of programmed cell death. Toxicol Pathol. 2007;35(4):495-516. doi:10.1080/01926230701320337

5. Chen R, Qi Q-L, Wang M-T, Li Q-Y. Therapeutic potential of naringin: an overview. Pharm Biol. 2016;54(12):3203-3210. doi:10.1080/ 13880209.2016.1216131

6. Li N, Whitaker C, Xu Z, Heggeness M, Yang S-Y. Therapeutic effects of naringin on degenerative human nucleus pulposus cells for discogenic low back pain. Spine J. 2016;16(10):1231-1237. doi:10.1016/j.spinee.2016.05.007

7. Kos N, Gradisnik L, Velnar T. A brief review of the degenerative intervertebral disc disease. Med Arch. 2019;73(6):421-424. doi:10.5455/ medarh.2019.73.421-424

8. Chen D, Xia D, Pan Z, et al. Metformin protects against apoptosis and senescence in nucleus pulposus cells and ameliorates disc degeneration in vivo. Cell Death Dis. 2016;7(10):e2441. doi:10.1038/cddis.2016.334

9. Cheng X, Zhang G, Zhang L, et al. Mesenchymal stem cells deliver exogenous miR-21 via exosomes to inhibit nucleus pulposus cell apoptosis and reduce intervertebral disc degeneration. J Cell Mol Med. 2018;22(1):261-276. doi:10.1111/jcmm.13316

10. Gopal D, Ho AL, Shah A, Chi JH. Molecular basis of intervertebral disc degeneration. Adv Exp Med Biol. 2012;760:114-133. doi:10.1007/9781-4614-4090-1_8

11. Song N, Zhao Z, Ma X, et al. Naringin promotes fracture healing through stimulation of angiogenesis by regulating the VEGF/VEGFR-2 signaling pathway in osteoporotic rats. Chem Biol Interact. 2017;261:11-17. doi:10.1016/j.cbi.2016.10.020

12. Xu X, Lai Y, Hua Z-C. Apoptosis and apoptotic body: disease message and therapeutic target potentials. Biosci Rep. 2019;39(1). doi:10.1042/ BSR20180992

13. He R, Cui M, Lin H, et al. Melatonin resists oxidative stress-induced apoptosis in nucleus pulposus cells. Life Sci. 2018;199:122-130. doi:10.1016/ j.lfs.2018.03.020

14. Eser B, Eser O, Aslan E, Dolgun H. The effects of polymorphisms of death pathway genes and mitochondrial pathway genes in intervertebral disc degeneration. Turk Neurosurg. 2017;27(5):809-815. doi:10.5137/1019-5149.JTN.17927-16.0

15. Han D, Ding Y, Liu S-L, et al. Double role of Fas ligand in the apoptosis of intervertebral disc cells in vitro. Acta Biochim Biophys Sin (Shanghai). 2009;41(11):938-947. doi:10.1093/abbs/gmp087

16. Tummers B, Green DR. Caspase-8: regulating life and death. Immunol Rev. 2017;277(1):76-89. doi:10.1111/imr.12541

17. Jeong S-Y, Seol D-W. The role of mitochondria in apoptosis. BMB Rep. 2008;41(1):11-22. doi:10.5483/bmbrep.2008.41.1.011

18. Zhao C-Q, Zhang Y-H, Jiang S-D, Jiang L-S, Dai L-Y. Both endoplasmic reticulum and mitochondria are involved in disc cell apoptosis and intervertebral disc degeneration in rats. Age (Dordr). 2010;32(2):161-177. doi:10.1007/s11357-009-9121-4

19. Choudhary GS, Al-Harbi S, Almasan A. Caspase-3 activation is a critical determinant of genotoxic stress-induced apoptosis. Methods Mol Biol. 2015;1219:1-9. doi:10.1007/978-1-4939-1661-0_1

20. Zhang J, Wang X, Liu H, et al. TNF- $\alpha$ enhances apoptosis by promoting chop expression in nucleus pulposus cells: role of the MAPK and NF- $\mathrm{KB}$ pathways. J Orthop Res. 2019;37(3):697-705. doi:10.1002/jor.24204

21. Yi S, Chen K, Zhang L, et al. Endoplasmic reticulum stress is involved in stress-induced hypothalamic neuronal injury in rats via the PERK-ATF4CHOP and IRE1-ASK1-JNK pathways. Front Cell Neurosci. 2019;13:190. doi:10.3389/fncel.2019.00190

22. Nusse R, Clevers H. Wnt/ß-catenin signaling, disease, and emerging therapeutic modalities. Cell. 2017;169(6):985-999. doi:10.1016/j. cell.2017.05.016

23. Holguin N, Silva MJ. In-vivo nucleus pulposus-specific regulation of adult murine intervertebral disc degeneration via Wnt/Beta-catenin signaling. Sci Rep. 2018;8(1):11191. doi:10.1038/s41598-018-29352-3

24. Buchtova M, Oralova V, Aklian A, et al. Fibroblast growth factor and canonical WNT/ $\beta$-catenin signaling cooperate in suppression of chondrocyte differentiation in experimental models of FGFR signaling in cartilage. Biochim Biophys Acta. 2015;1852(5):839-850. doi:10.1016/j. bbadis.2014.12.020

25. Yu L, Hao Y, Peng C, et al. Effect of Ginsenoside $\operatorname{Rg} 1$ on the intervertebral disc degeneration rats and the degenerative pulposus cells and its mechanism. Biomed Pharmacother. 2020;123:109738. doi:10.1016/j.biopha.2019.109738

26. Wawryk-Gawda E, Chylińska-Wrzos P, Lis-Sochocka M, et al. P53 protein in proliferation, repair and apoptosis of cells. Protoplasma. 2014;251 (3):525-533. doi:10.1007/s00709-013-0548-1

27. Novais EJ, Diekman BO, Shapiro IM, Risbud MV. p16Ink4a deletion in cells of the intervertebral disc affects their matrix homeostasis and senescence associated secretory phenotype without altering onset of senescence. Matrix Biol. 2019;82:54-70. doi:10.1016/j.matbio.2019.02.004

Drug Design, Development and Therapy

\section{Dovepress}

\section{Publish your work in this journal}

Drug Design, Development and Therapy is an international, peer-reviewed open-access journal that spans the spectrum of drug design and development through to clinical applications. Clinical outcomes, patient safety, and programs for the development and effective, safe, and sustained use of medicines are a feature of the journal, which has also been accepted for indexing on PubMed Central. The manuscript management system is completely online and includes a very quick and fair peer-review system, which is all easy to use. Visit http://www.dovepress.com/testimonials.php to read real quotes from published authors.

Submit your manuscript here: https://www.dovepress.com/drug-design-development-and-therapy-journal 